\title{
Systemic administration of pituitary adenylate cyclase-activating polypeptide maintains beta-cell mass and retards onset of hyperglycaemia in beta-cell-specific calmodulin-overexpressing transgenic mice
}

Shin Tsunekawa, Yoshitaka Miura, Naoki Yamamoto, Yuji Itoh ${ }^{1}$, Yoh Ariyoshi, Takao Senda ${ }^{2}$, Yutaka Oiso and Ichiro Niki ${ }^{1}$

Department of Endocrinology and Diabetology, Nagoya University School of Medicine, 65 Tsurumai-cho, Showa-ku, Nagoya 466-8550, Japan,

${ }^{1}$ Department of Pharmacology, Faculty of Medicine, Oita University, 1-1Hasama, Oita 879-5593, Japan and ${ }^{2}$ Department of Anatomy I,

Fujita Health University, School of Medicine, 1-98 Dengakugakubo, Kutsukake-cho, Toyoake 470-1192, Japan

(Correspondence should be addressed to I Niki; Email: niki@med.oita-u.ac.jp)

\begin{abstract}
Objective: Pituitary adenylate cyclase-activating polypeptide (PACAP) has been shown to play an important role in the regulation of islet function. We investigated its effects in beta-cell-specific calmodulin-overexpressing diabetic (CaMTg) mice, in which we consider that apoptosis of beta cells is the primary defect leading to basal hyperglycaemia.

Methods: CaMTg mice were treated with continuous s.c. infusions of PACAP from 2 to 4 weeks after birth, and were evaluated against littermate non-transgenic (nTg) and saline-treated CaMTg mice as to plasma glucose levels, insulin content, islet function and morphological features.

Results: Remarkable and progressive hyperglycaemia was observed in CaMTg mice, and PACAP treatment blunted this elevation. Insulin secretion from isolated islets demonstrated an impaired response to glucose in CaMTg mice, and PACAP treatment did not cause any improvement. The total pancreatic insulin content in CaMTg mice decreased significantly to $19.1 \%$ of that in nTg mice. PACAP treatment of CaMTg mice increased the content to $158 \%$ of the value in saline-treated CaMTg mice. The insulin content in isolated islets from CaMTg mice also decreased to $15.9 \%$ of that in nTg mice, while PACAP treatment caused a doubling of the value. Immunohistochemical investigation revealed that the insulin-positive islet area was markedly smaller in CaMTg mice and that PACAP treatment significantly expanded the insulin-positive islet area.

Conclusions: These findings indicate that PACAP treatment retards the onset of hyperglycaemia in CaMTg mice by maintaining beta-cell mass and PACAP treatment may potentially be a therapeutic measure for preventing beta-cell exhaustion during hyperglycaemia.
\end{abstract}

European Journal of Endocrinology 152 805-811

\section{Introduction}

Pituitary adenylate cyclase-activating polypeptide (PACAP) is a ubiquitous neuropeptide belonging to the secretin/glucagon/vasoactive intestinal polypeptide (VIP) superfamily, and exists in two amided forms, the 38 amino acid residue form (PACAP38) and the truncated 27 residue form (PACAP27). PACAP, originally isolated from the ovine hypothalamus (1), is a multifunctional neuropeptide that acts on a wide variety of cells including neural, immune and endocrine/exocrine cells (2). Although the proportion of PACAP38 to PACAP27 varies among the various organs, these isoforms share the same receptors and are equally potent (3). In endocrine cells, PACAP has been shown to play a positive role in the biosynthesis and release of various hormones, such as luteinising hormone and follicle-stimulating hormone from gonadotrophs, growth hormone $(\mathrm{GH})$ from somatotrophs, catecholamines from the adrenal gland, and insulin and glucagon from pancreatic islets (4). Apart from these actions as secretagogues, both forms of PACAP have been suggested to be involved in the proliferation, growth and survival of cerebellar granule cells and astrocytes $(5,6)$. PACAP binds three types of G-protein-coupled membrane receptors: PACAP type-1 receptor (PAC1-R), VIP/PACAP subtype-1 receptor (VPAC1-R) and VIP/PACAP subtype-2 receptor (VPAC2-R). PAC1-R is specific to PACAP, whereas VPAC1-R and VPAC2-R do not discriminate between PACAP and VIP. The aforementioned diverse effects of PACAP are due to the wide distribution of the peptide and its receptors, as 
well as to various effectors downstream: adenylate cyclase, phospholipase $\mathrm{C}$, the L-type $\mathrm{Ca}^{2+}$ channel and the mitogen activated protein kinases (7). The insulinotrophic effects of PACAP were first reported in mouse islets (8), and this was, then, proved to be due to the activation of VPAC2-R (9), although the involvement of other subtypes of PACAP receptor has been also suggested (10). A recent study demonstrated that daily injections of PACAP reduced blood glucose levels in diabetic Goto-Kakizaki rats, a polygenic model of type 2 diabetes, and high-fat-fed mice, in which the diet is associated with impaired glucose tolerance (11). It has also been documented that a VPAC2-selective agonist peptide, derived from a site-directed mutation of PACAP, increased serum insulin levels and lowered blood glucose in rats (12). Moreover, the beta-cellspecific overexpression of PACAP in vivo enhanced insulin secretion and rendered beta-cells resistant to streptozotocin (13). These findings point to PACAP as an antidiabetic agent. In the present study, we examined the effect of PACAP on the onset of diabetes and its protective effect against beta-cell decay in beta-cell-specific calmodulin-overexpressing transgenic (CaMTg) mice $(14,15)$, a diabetic animal model with $\mathrm{Ca}^{2+}$-dependent beta-cell exhaustion (16).

\section{Materials and methods}

\section{Minigene construct and the production of transgenic animals}

CaMTg mice, kindly provided by Prof. A R Means (Duke University, Durham, NC, USA), were produced as described previously (14). Briefly, the rat insulin-II promoter/chicken calmodulin cDNA chimeric gene was microinjected into mouse embryos derived from female FVB (Friend leukaemia virus B) mice, followed by the implantation of the embryos into pseudopregnant female FVB mice. The transgenic mice were subsequently bred into the CD1 (caesarean derived 1) strain and later into the ICR (Institute for Cancer Research) strain (16). These mice were housed in a temperature-, humidity- and light-controlled room $\left(21-23^{\circ} \mathrm{C}, 12 \mathrm{~h}\right.$ light: $12 \mathrm{~h}$ darkness cycle) with free access to food and water. They were characterised as having blepharostenosis at 2-3 weeks and frank hyperglycaemia at 4 weeks of age. In cases where earlier characterisation was necessary, genomic typing was carried out (see below). Male CaMTg mice were bred with normal female ICR mice (Japan SLC, Hamamatsu, Japan), because the female CaMTg mice were infertile. As controls, we used non-trangenic (nTg) mice from the same litters. All experiments using laboratory mice were approved by the University Committees on Animal Experiments in accordance with the Guidelines for Animal Experimentation in both Nagoya and Oita Universities.

\section{PACAP treatment}

Four groups of mice were studied: nTg mice with saline treatment, nTg mice with PACAP treatment, CaMTg mice with saline treatment and CaMTg mice with PACAP treatment. PACAP was purchased from the Peptide Institute (PACAP38; Osaka, Japan). Osmotic minipumps (Model 1002; Alzet, Cupertino, CA, USA) were implanted at the end of the second week after birth, and PACAP $(40 \mathrm{pmol} / \mathrm{g}$ of initial body weight $(\mathrm{BW}) /$ day) was s.c. injected during the following 14 days. After the implantation of the osmotic minipumps in the midscapular region, BW and plasma glucose levels were monitored daily. At the end of the experimental period, the pancreases were removed and weighed. For the measurement of the insulin content, pancreas samples were homogenised in ice-cold acidethanol solution $(0.18 \mathrm{~mol} / \mathrm{l} \mathrm{HCl}$ in $75 \%$ ethanol $)$ and centrifuged. The supernatants were diluted and neutralised with $0.1 \mathrm{~mol} / \mathrm{l}$ Tris-buffered saline $(\mathrm{pH}$ 8.0) and subjected to ELISA (Shibayagi, Tokyo, Japan). For the histochemical studies, the pancreases were fixed in $4 \%$ paraformaldehyde in $0.1 \mathrm{~mol} / \mathrm{l}$ phosphate buffer (pH 7.4) and embedded in paraffin.

\section{Genomic typing by PCR}

Genomic DNA was extracted from the tails of the mice 7 days after birth using the QIAamp DNA Mini Kit (Qiagen), and was subjected to PCR amplification of the chicken calmodulin transgene. The specific primer pairs (sense: 5'-GAGCCACCATGGCTGATCA-3'; antisense: 5'-CATGTCCTGTAATTCTGCTTCTGT-3') amplified a 200 bp product only in CaMTg mice. The results were confirmed by a comparison with the later phenotype of these mice.

\section{Plasma glucose measurement and i.p. glucose tolerance tests}

Plasma glucose concentrations were measured using a compact glucose analyser (MediSafe; Terumo, Tokyo, Japan). Blood samples were collected by tail cutting in the interval from 1000 to $1400 \mathrm{~h}$ from these mice, which were fed freely. I.p. glucose tolerance tests were performed after $8 \mathrm{~h}$ of fasting. Glucose $(2 \mathrm{mg} / \mathrm{g} \mathrm{BW})$ was i.p. injected into 4-week-old CaMTg and nTg mice with or without PACAP treatment.

\section{The size of the isolated pancreatic islets and insulin release}

Pancreatic islets were isolated from nTg and CaMTg mice with PACAP or saline treatment, using collagenase digestion. The sizes of 100 isolated islets from each experimental group were measured. The effects of PACAP on insulin release were studied using islets from PACAP- and saline-treated CaMTg mice and from PACAP- and saline-treated nTg mice. A group 
of three size-matched islets were placed into an incubation tube. After $30 \mathrm{~min}$ of preincubation in Hepesbuffered Krebs-Ringer solution (119 mmol/l $\mathrm{NaCl}$, $5.0 \mathrm{mmol} / \mathrm{l} \mathrm{NaHCO}_{3}, 4.75 \mathrm{mmol} / \mathrm{l} \mathrm{KCl}, 1.2 \mathrm{mmol} / \mathrm{l}$ $\mathrm{MgSO}_{4}, 2.54 \mathrm{mmol} / \mathrm{l} \mathrm{CaCl} 2,1.2 \mathrm{mmol} / \mathrm{l} \mathrm{KH}_{2} \mathrm{PO}_{4}$ and $20 \mathrm{mmol} / \mathrm{l}$ Hepes, at $\mathrm{pH} 7.4$ ) containing $0.5 \% \mathrm{BSA}$ (Fraction V; Sigma) and $3.3 \mathrm{mmol} / \mathrm{l}$ glucose (17), the islets were transferred to BSA-containing Hepes-buffered Krebs-Ringer solutions, with a low (3.3 mmol/l) or high $(20 \mathrm{mmol} / \mathrm{l})$ concentration of glucose. Both preincubation and incubation were performed at $37^{\circ} \mathrm{C}$ in a water bath. Samples were collected after $60 \mathrm{~min}$ of incubation for insulin determination with ELISA. The islet insulin content was also measured after ice-cold acid-ethanol extraction, as described above. Data are expressed as the rate of released insulin/islet insulin content.

\section{Light microscopy and immunohistochemistry}

The pancreases fixed in paraffin blocks were serially sectioned throughout their lengths, in order to avoid any bias from regional changes in islet distribution. The sections were stained with haematoxylin and eosin, and observed by light microscopy. For the immunohistochemical study, the fixed pancreases were washed thoroughly in PBS containing 10, 15 and then 20\% sucrose, embedded in Optimal Cutting Temperature (OCT) compound (Sakura, Tokyo, Japan), and frozen. The frozen sections were cut into $5 \mu \mathrm{m}$ thick slices and incubated for $1 \mathrm{~h}$ with anti-insulin guinea pig antibody (Seikagaku Kogyo, Tokyo, Japan) and anti-glucagon rabbit antibody (Zymed, San Francisco, CA, USA). After washing with PBS, they were further incubated for $1 \mathrm{~h}$ in a mixture of rhodamineconjugated anti-guinea pig IgG antibody (ICN, Costa Messa, CA, USA) and FITC-conjugated anti-rabbit IgG antibody (Vector, Burlingame, CA, USA). The sections were analysed with a confocal scanning laser microscope (MR-1024; Japan Bio-Rad, Tokyo, Japan). The insulin-positive areas were quantitatively evaluated based on 100 islets from each group using $\mathrm{NIH}$ Image software.

\section{Statistical analysis}

Data are expressed as means \pm S.E. The statistical significance was estimated by Student's t-test or one-way ANOVA, followed by post-hoc Bonferroni analysis using StatView 5 (SAS Institute, Inc., Cary, NC, USA). A $P$ value of $<0.05$ was considered statistically significant.

\section{Results}

\section{The effects of PACAP on plasma glucose levels}

In nTg mice, plasma glucose levels gradually rose to $7 \mathrm{mmol} / \mathrm{l}$ during the first 4 weeks after birth, and
PACAP did not exert any appreciable effect on plasma glucose levels. In CaMTg mice, acute and steep elevation of the plasma glucose levels was observed, the levels reaching $15 \mathrm{mmol} / \mathrm{l}$ at the end of the experimental period. Continuous and s.c. administration of PACAP apparently blunted the elevation of the plasma glucose levels in CaMTg mice (Fig. 1). The profiles of the gradual increase in BW throughout the period did not differ among these four groups (data not shown), suggesting that the glucose-lowering effects were not due to the suppression of appetite. Serum insulin levels were often undetected. In the i.p. glucose tolerance tests, sustained hyperglycaemia in CaMTg mice was not influenced by PACAP treatment.

\section{Islet isolation and insulin secretion experiments}

The yield of islets from CaMTg mice was much lower than that from nTg mice. Light-microscopic observation revealed that isolated islets from CaMTg mice were significantly smaller than those from nTg mice. PACAP treatment stabilised the size of the isolated islets in CaMTg mice $(92.2 \pm 2.5 \mu \mathrm{m}$ for $\mathrm{nTg} /$ saline, $101.3 \pm 2.1 \mu \mathrm{m}$ for nTg/PACAP, $63.9 \pm 2.3 \mu \mathrm{m}$ for CaMTg/saline and $76.3 \pm 3.5 \mu \mathrm{m}$ for $\mathrm{CaMTg} / \mathrm{PACAP}$ ) (Fig. 2), although the yield was similar to that of saline-treated CaMTg mice. PACAP treatment did not alter the size and yield of the islets in nTg mice. In the secretion experiments, the basal levels of insulin secretion from CaMTg islets with or without PACAP treatment were much lower than those from nTg islets (Fig. 3). However, when expressed as the rate of released insulin/insulin content, the value for PACAPtreated CaMTg islets was apparently higher than that

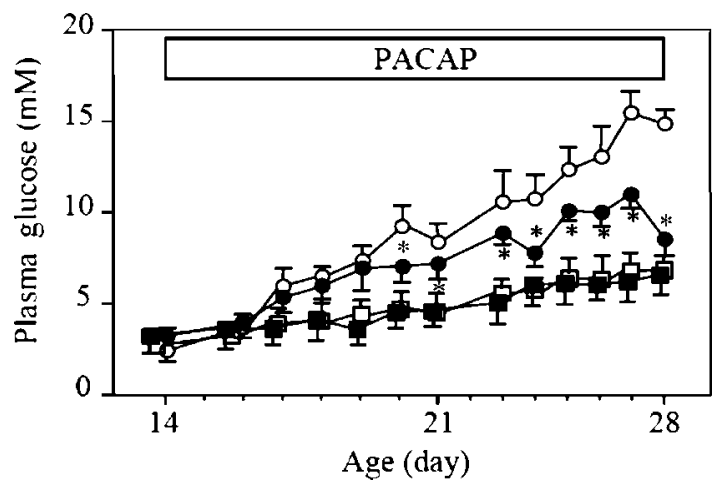

Figure 1 The plasma glucose levels of PACAP-treated and saline-treated CaMTg mice. PACAP $(40 \mathrm{pmol} / \mathrm{g}$ of initial BW/day) was given s.c. and continuously, using osmotic minipumps from 14 to 28 days after birth, as indicated by the boxed area. Blood samples were taken by tail cutting, and plasma glucose levels were measured using a compact glucose analyser. - PACAPtreated CaMTg mice $(n=10)$; $~$ saline-treated CaMTg mice $(n=16)$; PACAP-treated $\mathrm{nTg}$ mice $(n=12)$; $\square$ saline-treated $n T g$ mice $(n=15)$. Each symbol represents a mean \pm S.E. value. ${ }^{\star} P<0.05$, as compared with the corresponding value in salinetreated CaMTg mice. 


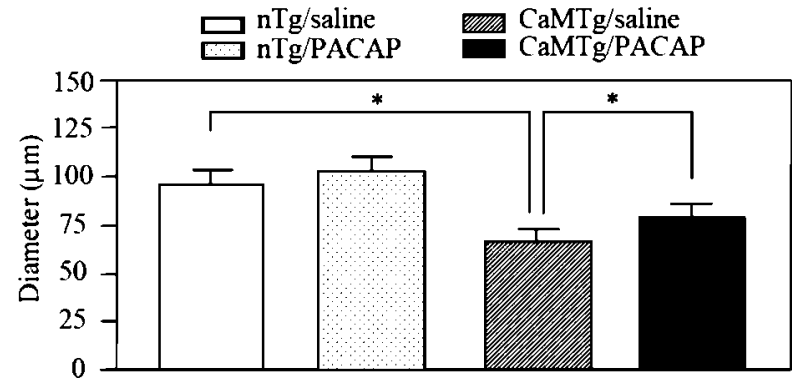

Figure 2 Comparison of the sizes of the isolated islets. Pancreatic islets were isolated from saline-treated $\mathrm{nTg}, \mathrm{PACAP}$-treated $\mathrm{nTg}$, saline-treated CaMTg and PACAP-treated CaMTg mice. A group of 100 islets from each group were observed under a microscope, and the size of each islet was analysed by $\mathrm{NIH}$ Image software. Each column represents a mean \pm S.E. value. ${ }^{\star} P<0.05$.

for saline-treated CaMTg islets. The islets from nTg mice showed an 8.9-fold increase of insulin secretion by $20 \mathrm{mmol} / \mathrm{l}$ glucose, while those from saline-treated CaMTg mice failed to respond to $20 \mathrm{mmol} / \mathrm{l}$ glucose. PACAP treatment did not improve the response of CaMTg islets to glucose.

\section{The effects of PACAP on the pancreatic insulin content}

As shown in Fig. 4, pancreatic insulin content in CaMTg mice was significantly lower $(74.5 \%$ of the content in saline-treated nTg mice at the age of 2 weeks), although nTg and CaMTg mice did not differ in their plasma glucose concentrations. The insulin content in nTg mice increased with age, while the increase with age was minimal in CaMTg mice; the content in CaMTg mice was only $19.1 \%$ of that in nTg mice at the end of the experimental period. Following this reduction in the insulin reserves, the progression to

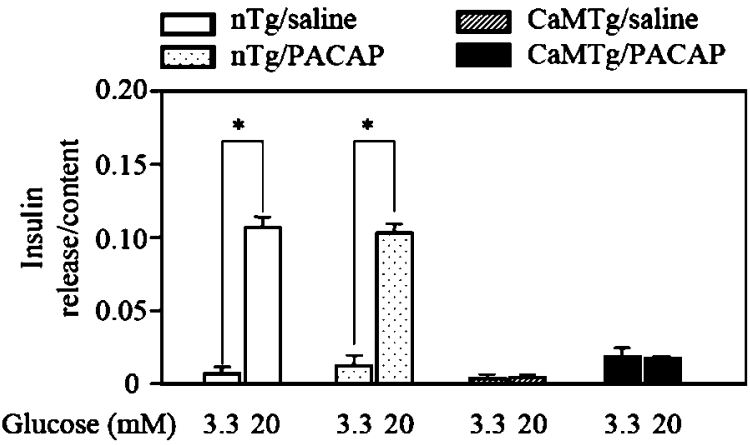

Figure 3 The effects of PACAP treatment on glucose-induced insulin release from isolated pancreatic islets. Pancreatic islets were isolated from saline-treated $\mathrm{nTg}$, PACAP-treated $\mathrm{nTg}$, saline-treated CaMTg and PACAP-treated CaMTg mice. The effect of glucose on insulin release was tested by static incubation $(n=15)$, performed with buffers containing $3.3 \mathrm{mmol} / \mathrm{l}$ or $20 \mathrm{mmol} / \mathrm{l}$ glucose. Secreted insulin during $60 \mathrm{~min}$ of incubation and the insulin content of the islets were determined with ELISA. Data are expressed as means \pm S.E. of the rates of secreted insuli$\mathrm{n} /$ insulin content. ${ }^{*} P<0.05$ vs $3.3 \mathrm{mmol} / \mathrm{l}$ glucose.

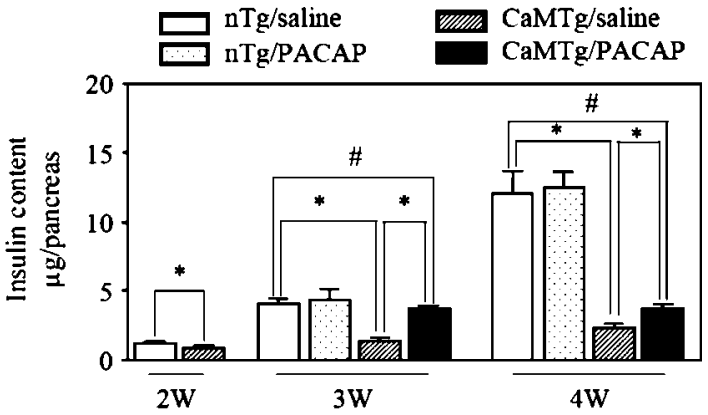

Figure 4 Total pancreatic insulin content. The pancreases from saline-treated $\mathrm{nTg}(n=18)$, PACAP-treated $\mathrm{nTg}(n=10)$, PACAP-treated CaMTg $(n=10)$ and saline-treated CaMTg mice $(n=10)$ were homogenised in ice-cold acid-ethanol solution and centrifuged. The supernatants were subjected to ELISA for insulin determination. Each column represents a mean \pm S.E. value. ${ }^{*} P<0.05$ vs nTg mice; ${ }^{\#} P<0.05$ vs saline-treated CaMTg mice.

hyperglycaemia occurred. PACAP treatment had no effect on the insulin content in nTg mice $(102.5 \%$ of the content in saline-treated nTg mice), but it boosted the pancreatic insulin content in CaMTg mice to 277 and $158 \%$ of the content in saline-treated CaMTg mice after 1 and 2 weeks of treatment respectively.

\section{The effects of PACAP treatment on insulin content in isolated pancreatic islets}

The insulin content in isolated islets from 4-week-old CaMTg mice was $15.9 \%$ of that from nTg mice of the same age $(84.0 \pm 5.3 \mathrm{ng} /$ islet for $\mathrm{nTg}$ and $13.3 \pm$ $2.9 \mathrm{ng} /$ islet for CaMTg). In nTg islets, PACAP treatment did not change the insulin content, while in CaMTg islets it markedly increased the insulin content to $213 \%$ of the saline-treated CaMTg islet value. Thus, the PACAP-induced increase of insulin content in islets may be involved in the glucose-lowering effects of PACAP in CaMTg mice.

\section{Histological and morphometrical studies}

Haematoxylin and eosin staining revealed very small CaMTg pancreatic islets, and PACAP treatment apparently increased their size and number. The pancreatic islets in saline-treated nTg mice were round in shape, whereas those from saline-treated CaMTg mice were irregular in outline (Fig. 5a and d, and b and e). The sizes of the individual CaMTg islet cells were apparently small, while the sizes of the nuclei were similar, indicating that the decrease was due to the reduction in cytoplasmic volume. PACAP treatment attenuated these morphological changes (Fig. 5c and f). Immunohistochemical study demonstrated a good organisation of the islet endocrine cells in nTg mice, with a central core of beta cells and a peripheral array of alpha cells (Fig. 6a). A marked decrease in insulin-positive cells was observed in the islets from CaMTg mice with the destruction of the organisation of the endocrine cells 
a

b

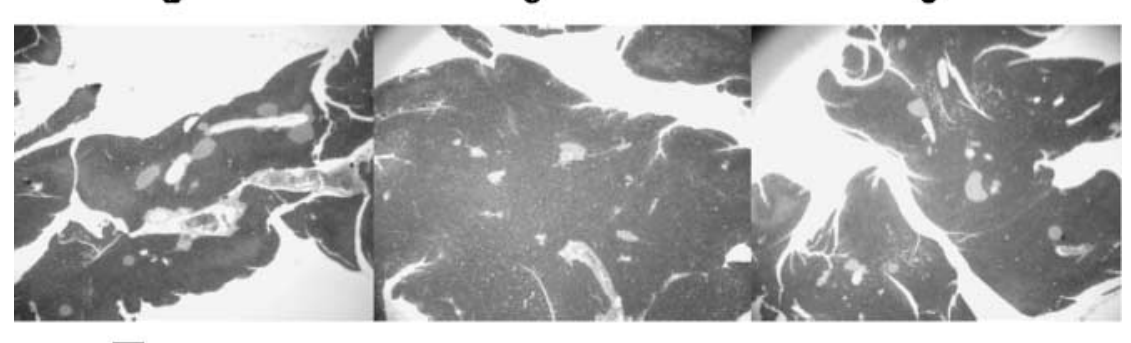

d

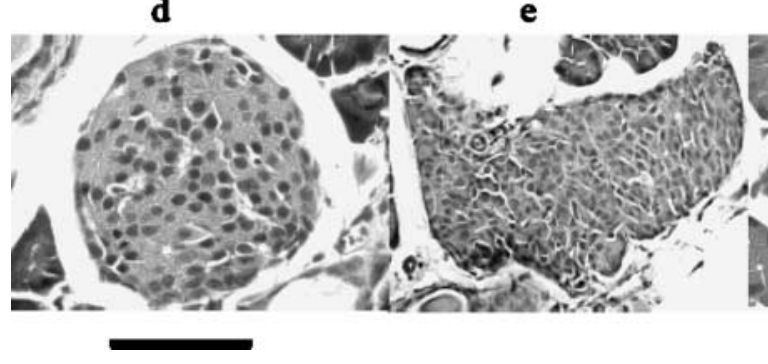

f

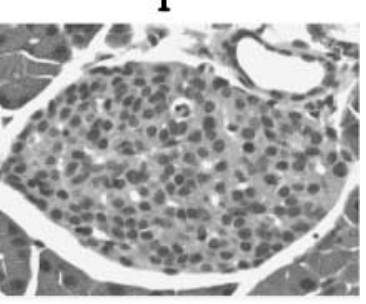

Figure 5 Haematoxylin and eosin staining of pancreatic islets. The pancreases from saline-treated $n T g(a, d)$, salinetreated CaMTg (b, e) and PACAP-treated CaMTg mice $(c, f)$ were fixed with $4 \%$ paraformaldehyde, embedded in paraffin, sectioned and stained with haematoxylin and eosin. The magnification is $\times 20$ in the upper figures. $(a-c)$ and $\times 400$ in the lower figures. $(d-f)$. The short bar for $(a-c)$ and the long bar for $(d-f)$ represent $100 \mu \mathrm{m}$.
(Fig. 6b). PACAP treatment enlarged both the insulinand the glucagon-immunopositive regions (Fig. 6c and $\mathrm{d}$ ), although PACAP treatment had no effect on the spatial derangement of the endocrine cells in the islets. Statistical analysis with 100 islets from three mice from each group revealed that PACAP treatment (a)

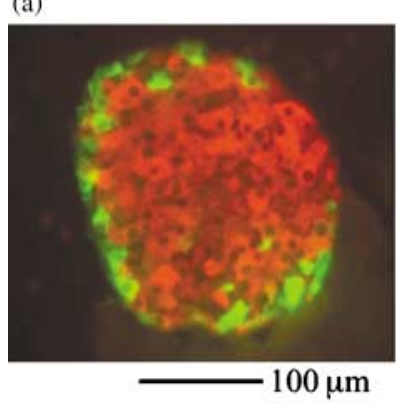

(c)

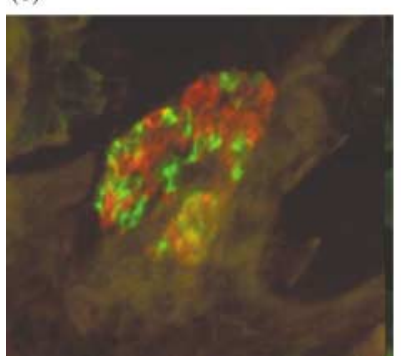

(b)

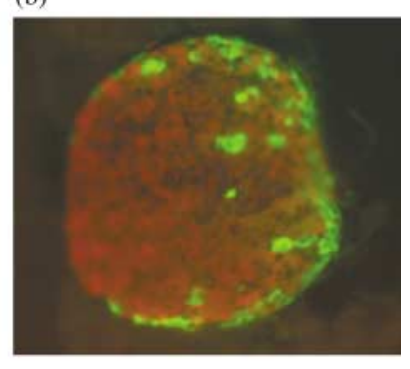

(d)

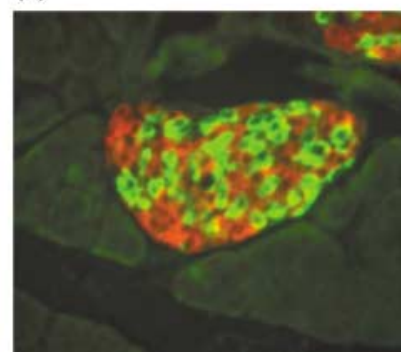

Figure 6 Immunohistochemical staining of the pancreas. Frozen sections of the pancreases from saline-treated nTg (a), PACAPtreated $\mathrm{nTg}(\mathrm{b})$, saline-treated CaMTg (c) and PACAP-treated CaMTg mice (d) were incubated with anti-insulin and anti-glucagon antibodies, followed by incubation in a mixture of rhodamine-conjugated anti-guinea pig IgG and FITC-conjugated $\lg \mathrm{G}$ anti-rabbit antibodies. Red $=$ insulin. Green = glucagons. significantly expanded the insulin-positive area in CaMTg mice (Fig. 7).

\section{Discussion}

We previously found that a $\mathrm{Ca}^{2+} /$ calmodulin-dependent and constitutive isoform of nitric oxide synthase (NOS) was present in beta cells, and that the timedependent beta-cell decay in CaMTg mice was partially prevented by daily i.p. injections of the NOS inhibitor $\mathrm{N}^{\omega}$-nitro-L-arginine methyl ester (L-NAME) (16). We here demonstrate that chronic and systemic administration of PACAP more consistently retards progression to diabetes in CaMTg mice than L-NAME did.

The antidiabetic effects of PACAP, also reported in other diabetic models, were mostly interpreted as a result of its potent insulinotrophic effect on the beta cell. The present findings, however, suggest to us

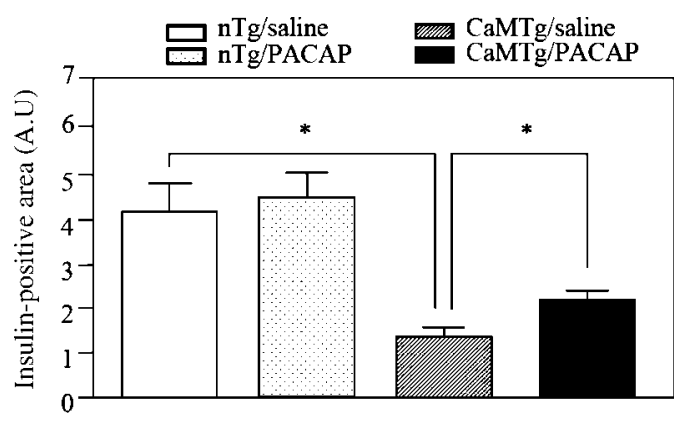

Figure 7 Comparison of the insulin-positive areas in the pancreatic islets. Immunostained pancreatic sections were observed under a confocal scanning laser microscope, followed by quantitative analysis of insulin-positive areas by NIH Image software. Each column represents a mean \pm S.E. value. ${ }^{\star} P<0.05$. 
that the beneficial effects of PACAP are mainly due to its protective effect on beta-cell mass rather than its direct effect on the secretory process, firstly because PACAP treatment did not improve the impaired insulin response to glucose stimulation from isolated CaMTg islets, and secondly because the serum insulin levels in CaMTg mice were not altered by the treatment. However, we cannot entirely eliminate the possibility that PACAP did increase in vivo insulin release in CaMTg mice but within an undetected range. The effect of PACAP on beta-cell mass could be explained by its prevention of the reduction of beta-cells (apoptosis) and/or its activation of betacell proliferation and neogenesis. We speculate that the protection of beta cells from apoptosis is more relevant for the PACAP action, because PACAP treatment failed to influence beta-cell mass and the pancreatic insulin content in $\mathrm{nTg}$ mice in the present study. This is consistent with a recent report that beta-cell-specific overexpression of PACAP in vivo not only potentiated insulin secretion but also rendered beta cells resistant to streptozotocin (13). Extrapancreatic effects may also participate in the antidiabetic actions, because PACAP is reported to increase glucose uptake into cultured adipocytes (18).

It should be noted that other hormones or pharmacological substances which elevate cAMP levels also protect beta cells against apoptotic cell death. Glucagonlike peptide 1 and its lizard homologue, exendin-4, are known to possess a highly potent insulinotrophic effect, and to stimulate cAMP production in the betacell by activating adenylate cyclase. Chronic treatment with these substances has been reported to improve hyperglycaemia in diabetic animals as well as in human diabetic subjects, but increased serum insulin levels are not always associated with such treatments (19-21). In in vitro studies, these substances are reported to possess protective effects against beta-cell death caused by various types of cell toxicity, including combinations of cytokines, where NO plays a critical role in beta-cell apoptosis $(22-24)$.

We have previously reported that PACAP reduced the rate of cytokine-induced apoptosis in cultured beta TC insulinoma cells (25). These findings were originally interpreted as a result of the inhibition of inducible NOS expression. However, suppression of the enzymatic activity or the subsequent apoptotic processes might also be involved in the prevention of beta-cell apoptosis by PACAP.

Relatively little information is available on the molecular mechanisms involved in the expansion of beta-cell mass. Some molecules implicated in insulin signalling, such as insulin receptor substrate (IRS) proteins and Akt/protein kinase B, have been reported to participate in beta-cell survival (26). We have very limited knowledge of the cAMP-dependent control of beta-cell mass. In this respect, a recent study indicating that induction of IRS-2 by cAMP signalling via phosphorylation of CREB may prevent beta-cell apoptosis is highly interesting (27).

\section{Acknowledgements}

The authors are grateful to Prof. A R Means (Duke University) for his generous gift of the CaMTg mice used in this study. This work was supported in part by two Grants-in-Aid for Scientific Research (Nos 13671183 and 13470006) from the Japan Society for the Promotion of Science, a research grant from the Japan Insulin Study Group, a grant from the Research for the Future Program of the Japan Society for the Promotion of Science (JSPS-RFTF97I00201), and by grants from the Japan Research Foundation for Clinical Pharmacology and from the Suzuken Memorial Foundation.

\section{References}

1 Miyata A, Arimura A, Dahl RR, Minamino N, Uehara A, Jiang L, Culler MD \& Coy DH. Isolation of a novel 38 residue-hypothalamic polypeptide which stimulate adenylate cyclase in pituitary cells. Biochemical and Biophysical Research Communications 1989 $164567-574$.

2 Vaudry D, Gonzalez BJ, Basille M, Yon L, Fournier A \& Vaudry H. Pituitary adenylate cyclase-activating polypeptide and its receptors: from structure to functions. Pharmacological Review 2000 52 269-324.

3 Arimura A. Perspectives on pituitary adenylate cyclase-activating polypeptide (PACAP) in the nueroendocrine, endocrine, and nervous systems. Japanese Journal of Physiology $1998 \mathbf{4 8} 301-331$.

4 Sherwood NM, Krueckl SL \& McRory JE. The origin and function of the pituitary adenylate cyclase-activating polypeptide (PACAP)/glucagon superfamily. Endocrine Reviews 200021 619-670.

5 Vaudry D, Rousselle C, Basille M, Falluel-Morel A, Pamantung TF, Fontaine M, Fournier A, Vaudry H \& Gonzalez BJ. Pituitary adenylate cyclase-activating polypeptide protects rat cerebellar granule neurons against ethanol-induced apoptotic cell death. PNAS 200299 6398-6403.

6 Ashur-Fabian O, Giladi E, Brenneman DE \& Gozes I. Identification of VIP/PACAP receptors on rat astrocytes using antisense oligonucleotides. Journal of Molecular Neuroscience 19979 11-22.

7 Vaudry D, Gonzalez BJ, Basille M, Yon L, Fournier A \& Vaudry H. Pituitary adenylate cyclase-activating polypeptide and its receptors: from structure to functions. Pharmacological Reviews 2000 52 269-324.

8 Fridolf T, Sundler F \& Ahren B. Pituitary adenylate cyclase-activating polypeptide (PACAP): occurrence in rodent pancreas and effect on insulin and glucagon secretion in the mouse. Cell and Tissue Research $1992 \mathbf{2 6 9} 275-279$.

9 Borboni P, Porzio O, Pierucci D, Cicconi S, Magnaterra R, Federici M, Sesti G, Lauro D, D'Agata V, Cavallaro S \& Marlier LN. Molecular and functional characterization of pituitary adenylate cyclase-activating polypeptide (PACAP-38)/vasoactive intestinal polypeptide receptors in pancreatic beta-cells and effects of PACAP-38 on components of the insulin secretory system. Endocrinology $19991405530-5537$.

10 Filipsson K, Kvist-Reimer M \& Ahren B. The neuropeptide pituitary adenylate cyclase-activating polypeptide and islet function. Diabetes 200150 1959-1969.

11 Yada T, Sakurada M, Filipsson K, Kikuchi M \& Ahren B. Intraperitoneal PACAP administration decreases blood glucose in GK rats, 
and in normal and high fat diet mice. Annals of the New York Academy of Sciences 2000921 259-263.

12 Tsutsumi M, Claus TH, Liang Y, Li Y, Yang L, Zhu J, Dele Cruz F, Peng X, Chen H, Yung SL, Hamren S, Livingston JN \& Pan CQ. A potent and highly selective VPAC2 agonist enhances glucoseinduced insulin release and glucose disposal: a potential therapy for type 2 diabetes. Diabetes 200251 1453-1460.

13 Yamamoto K, Hashimoto H, Tomimoto S, Shintani N, Miyazaki J, Tashiro F, Aihara H, Nammo T, Li M, Yamagata K, Miyagawa J, Matsuzawa Y, Kawabata Y, Fukuyama Y, Koga K, Mori W, Tanaka K, Matsuda T \& Baba A. Overexpression of PACAP in transgenic mouse pancreatic beta-cells enhances insulin secretion and ameliorates streptozotocin-induced diabetes. Diabetes 2003 52 1155-1162.

14 Epstein PN, Ribar TJ, Decker GL, Yaney G \& Means AR. Elevated $\beta$-cell calmodulin produces a unique insulin secretory defect in transgenic mice. Endocrinology 1992130 1387-1393.

15 Ribar TJ, Epstein PN, Overbeek PA \& Means AR. Targeted overexpression of an inactive calmodulin that bind $\mathrm{Ca}^{2+}$ to the mouse pancreatic $\beta$-cell results in impaired secretion and chronic hyperglycemia. Endocrinology 1995136 106-115.

16 Yu W, Niwa T, Miura Y, Horio F, Teradaira S, Gibar TJ, Means AR, Hasegawa Y, Senda T \& Niki I. Calmodulin overexpression causes $\mathrm{Ca}^{2+}$-dependent apoptosis of pancreatic beta cells which can be prevented by inhibition of nitric oxide synthase. Laboratory Investigation 200282 1229-1239.

17 Niwa T, Nimura Y \& Niki I. Lack of effect of incretin hormones on insulin release from pancreatic islets in the bile duct-ligated rats. American Journal of Physiology. Endocrinology and Metabolism 2001 280 E59-E64.

18 Yada T, Nakata M \& Shioda S. Insulinotropin PACAP potentiates insulin action. Stimulation of glucose uptake in 3T3-LI adipocytes. Annals of the New York Academy of Sciences 2000921 $473-477$.

19 Tourrel C, Bailbe D, Lacorne M, Meile MJ, Kergoat M \& Portha B. Persistent improvement of type 2 diabetes in the Goto-Kakizaki rat model by expansion of the beta-cell mass during the prediabetic period with glucagon-like peptide-1 or exendin-4. Diabetes 200251 1443-1452.
20 Greig NH, Holloway HW, De Ore KA, Jani D, Wang Y, Zhou J, Garant MJ \& Egan JM. Once daily injection of exendin-4 to diabetic mice achieves long-term beneficial effects on blood glucose concentrations. Diabetologia 199942 45-50.

21 Tourrel C, Bailbe D, Meile MJ, Kergoat M \& Portha B. Glucagonlike peptide- 1 and exendin-4 stimulate beta-cell neogenesis in streptozotocin-treated newborn rats resulting in persistently improved glucose homeostasis at adult age. Diabetes 200150 $1562-1570$

22 Li Y, Hansotia T, Yusta B, Ris F, Halban PA \& Drucker DJ. Glucagon-like peptide-1 receptor signaling modulates beta cell apoptosis. Journal of Biological Chemistry 2002278 471-478.

23 Drucker DJ. Glucagon-like peptides: regulators of cell proliferation, differentiation, and apoptosis. Molecular Endocrinology 200317 $161-171$.

24 Farilla L, Bulotta A, Hirshberg B, Calzi SL, Khoury N, Noushmehr H, Bertolotto C, Mario UD, Harlan DM \& Perfetti R. Glucagon-like peptide 1 inhibits cell apoptosis and improves glucose responsiveness of freshly isolated human islets. Endocrinology $20031445149-5158$.

25 Sekiya K, Nagasaki H, Ozaki N, Suzuki A, Miura Y \& Oiso Y. Pituitary adenylate cyclase-activating polypeptide prevents cytokineinduced cytotoxicity via inhibition of inducible nitric oxide synthase expression in beta TC cells. Biochemical and Biophysical Research Communications 2000278 211-216.

26 Dickson LM \& Rhodes CJ. Pancreatic beta-cell growth and survival in the onset of type 2 diabetes: a role for protein kinase B in the Akt? American Journal of Physiology. Endocrinology and Metabolism 2004287 E192-E198.

27 Jhala US, Canettieri G, Screaton RA, Kulkarni RN, Krajewski S, Reed J. Walker J. Lin X, White M \& Montminy M. cAMP promotes pancreatic beta-cell survival via CREB-mediated induction of IRS2. Genes and Development 200317 1575-1580.

Received 9 November 2004

Accepted 11 February 2005 